\title{
Introduction to heritage and development: the agency of heritage in rural and urban development practices
}

\section{Annelie Sjölander-Lindqvist}

This section explores a variety of cases around development in relation to heritage. In planning, heritage and development were long seen as opposites, so that heritage had to be protected from development. In recent decades, this narrative has changed; now, heritage is often argued to be a crucial asset in urban development and regeneration processes (Corten et al. 2014). Heritage is seen as an integral part of society that can be pivotal in supporting cohesion and providing routes towards smarter, more sustainable and more inclusive societies in the longer term, as also evidenced by its inclusion in the Sustainable Development Goals (UN 2016).

For better or worse, heritage is a globalized economic commodity (Guzmán et al. 2017; Pendlebury and Porfyriou 2017). It can be used to promote locally rooted economic development and help balance the globalization-caused fragmentation of local livelihoods. Think, for example, about how micro-entrepreneurs can leverage their skills, resisting the growing mega-forces of food capitalism and large-scale tourism. Moreover, heritage-informed practices can be integrated into planning to incentivize and inspire more locally anchored spatial developments and policies. As prominently addressed in the 'Integrated approach to cultural heritage for Europe', heritage is an 'irreplaceable repository of knowledge and valuable resource for economic growth, employment and social cohesion' (European Commission 2014c). This acknowledges heritage's qualities, both tangible and intangible; indicating places, buildings and objects as foundations, as important as memories, emotions, stories, practices and meanings.

Realizing these abilities requires a policy context and planning process that are culturally sensitive, prepared to balance natural and cultural heritage values, 
and able to catalyse entrepreneurial capacity. This section is concerned with the role that heritage can play in development; how the value and potential of cultural heritage can be responsibly used as resources for sustainable development and enhanced pride in place and quality of life in a constantly evolving society; and how policy, between the past and possible futures of places, can harness the potentials of different heritage expressions, to support sustainable resource use and development, while being attentive to both traditional and more recent or new practices.

This framework reinforces how heritage, if utilized sensitively and sustainably, can have a positive impact on development, well-being, recreation and tourism. This does not imply that development strategies only focus on the commodifiable, 'useful' and 'convenient' histories and heritages, which often prevent various groups from developing a sense of belonging (e.g. Hall 1999; Sinclair-Chapman 2018; Veldpaus and Pendlebury 2019). Our argument is that, for heritage to be an effective and sustainable resource for development and to enhance pride in place and quality of life, policy, governance and regulation must be prepared to reimagine the role the past may have for the sustainable society. To support traditional and vibrantly contemporary practices, while being attentive to cultural diversity, the trans-local flows of capital and labour, gendered aspects, mobile communities, goods, technology and representations, the roles and perceptions of various actors must take centre stage. Since individuals and groups articulate, understand and value cultural significance differently, policy and planning need to acknowledge the intangible and tangible qualities of heritage. Places and landscapes, built sites, historical structures, objects and artefacts should therefore be approached as intermediaries and materials for memories, emotions, stories, myths, practices and meanings. Simply, the social worlds and everyday lives of local actors and local groups are critical to the effectiveness of attempts by policy sectors to stimulate local and regional development. It needs also to be remembered that heritage, represented by built sites and artefacts, songs, stories, brogues, practices, myths, and the memories of people and local communities, contributes to our local, regional and national identities.

Recognizing these dimensions and the consideration of heritage as an asset or vector for local and regional development, and how heritage can support cohesion and sense of belonging in a world that appears to be increasingly fragmentized, the three chapters in this section address and demonstrate how heritage can be approached as a node not only for social and human capital, but also in terms of potential for economic development. The chapters demonstrate how heritage is a social process of giving meaning, emerging through the process of performance, coming into being through concerted, fortuitous, 
embodied and lived practices. They amplify the idea that cultural heritage, if responsibly used as a resource for sustainable development, can bridge the past and possible futures of objects, places and landscapes; they demonstrate how heritage planning and management creates what Toda (1976) describes as 'nested situations'. All the interrogated cases exemplify the dynamics associated with handling issues that are confined by socially, culturally, politically and economically framed commitments.

In the chapter 'Cultural heritage and improvised music in European festivals', Tony Whyton and Beth Perry discuss the to-date-undervalued position of festivals and improvised music in a European heritage context. They identify improvising, marketing and sounding jazz as nodes for analysing the relationship between heritage and place. An interesting and challenging proposition is that music festivals represent a fluid heritage, management of which is both difficult and critical. Festivals perpetuate unequal boundaries and xenocentrism, and open up the possibility for marginalized groups not only to take part in, but also to develop their own cultural activities. The next chapter, 'Cultural heritage at work for economy and society', by Stefano Della Torre and Rossella Moioli, reveals the potentialities of integrated approaches to cultural heritage management by comparing three models that aim to achieve more effective management of cultural resources (in this case, built heritage). Turning its sights to the Netherlands, the Flanders province of Belgium, Italy and Sweden, the research project has a people-centred focus, interviewing stakeholders in order to define and compare the capacity of the models to organize sustainable interventions, to mobilize durable funding, and to involve people and communities, as well as to identify the skills required to support the transition in built heritage activities from acute to more sustainable and preventive conservation schemes. The final chapter is 'Gastronomy and creative entrepreneurship in rural tourism: encouraging sustainable community development', in which Annelie Sjölander-Lindqvist, Anna de Jong, Romà Garrido, Giuseppa Romeo and Wilhelm Skoglund discuss how small-scale businesses can be understood as sites where the 'cultural becomes political', a term used to describe the intersection of locality, community and practices carried out and forming the basis for alternative development. Including case studies from four countries in Europe, their project studies how the innovative use of different cultural dimensions, and tangible and intangible properties of places and landscapes, can support the development and creation of new employment opportunities and stimulate economic development. This is not least important for rural areas, since small businesses can boost economic and social resilience.

The three chapters unite in demonstrating how heritage can inculcate the 'social glue' of communities. In light of the objectives of European Union 
policy in the areas of participatory governance, integrated approaches, strategic and sustainable development and identity (European Commission 2014a, 2014b, 2014c), and the Lisbon Treaty (European Commission 2007), heritage is identified as a vital resource for the implementation of the sustainable development objectives. This is now also globally recognized, as evidenced by heritage and culture being integral parts of the United Nations Sustainable Development Goals (for further analysis, see Labadi and Logan 2015; Pereira Roders and Bandarin 2019; UNESCO 2016).

Given the wide range of ways in which people relate to and value land and sea, we suggest that cultural values need to be defined by the stakeholders, rights holders and communities of interest within the planning area. While there are distinct advantages of heritage - in providing, for example, continuity and stability - there are also potential tensions and power asymmetries that must be continuously interrogated and acknowledged. This includes understanding of what promotes greater sense of ownership and commitment to actions implemented to utilize and embrace different forms of capital (actors, material/immaterial resources, places, spatial connectivity and power); how the commercialization of heritage may compromise conservation and/or environmental sustainability values or result in gentrification and exclusion instead of cohesion; and how varied types of knowledge, understandings and perspectives can be consolidated to establish legitimate actions, solutions and strategies in a fragmented world.

Accommodating the concerned parties' understandings and conceptualizations of heritage and associated dimensions should, however, be accompanied by critically asking about the value frameworks informing heritage planning and management. The importance of this question arises from the understanding that heritage is embedded within different frameworks of meaning and rationales of action. These may not always be compatible, thereby creating a need to explore conceptual and practical challenges associated with measures intended to overcome friction (Sjölander-Lindqvist et al. 2015; Sjölander-Lindqvist et al. 2018). As suggested by Strang (2009), 'there is need to consider not just the formal institutions' (p. 5), but also the 'social complexities, diverse subcultural perspectives, and material opportunities and constraints' (p. 6). Colebatch (2010) suggests similarly that 'different frameworks of meaning and rationales of action' (p. 31) will be mobilized by the interweaving of diverse actors, all of whom have their own agendas and values that influence their participation in planning and management. The three chapters in this section gather in the understanding that heritage should be appreciated as a bounded space for human thought and action, including both material and immaterial values 
and meanings that will underpin its planning and management. These actions embed and reflect domains of meaning (Shore et al. 2011).

Summing up, it can be stated that heritage emerges as an arena confined by actors' understandings and representations. This establishes planning and management as nested and heritage as 'social', in the sense that heritage resources are driven by idealized probabilities and attributes. As a shared space for human experience, imagination and significance, conservation and preservation become defined by political, economic and cultural structures, values and relationships. These realities of life, or interdependencies, must be recognized to achieve social sustainability. Some concerns are shared, others are not. All in all, the studied cases echo broader issues of entitlement to resources and value transformation that can stabilize but also disturb or even disrupt sustainability.

\section{References}

Colebatch, H. (2010), 'Giving accounts of policy work', in H. Colebatch, R. Hoppe and M. Noordegraaf (eds), Working for Policy, Amsterdam: Amsterdam University Press, 31-44.

Corten, J.P, E. Geurts, P. Meurs and R. Vermeulen (eds) (2014), Heritage as an Asset for Inner-City Development, Rotterdam: NAi010.

European Commission (2007), C 306/1 'Treaty of Lisbon: amending the treaty on European union and the treaty establishing the European Community', Official Journal of the European Union, 2007/C 306/01, https://eur-lex.europa.eu/legal -content/EN/TXT/?uri=CELEX\%3A12007L\%2FTXT (accessed 19 July 2019).

European Commission (2014a), 'Council conclusions on cultural heritage as strategic resource for a sustainable Europe', Official Journal of the European Union, 2014/C 183/08, https://eur-lex.europa.eu/legal-content/EN/TXT/?uri=CELEX \%3A52014XG0614\%2808\%29 (accessed 19 July 2019).

European Commission (2014b), 'Council conclusions on participatory governance of cultural heritage', Official Journal of the European Union, 2014/C 463/01, https://eur-lex.europa.eu/legal-content/EN/TXT/PDF/?uri=CELEX:52014XG1223( 01)andfrom=EN (accessed 19 July 2019).

European Commission (2014c), 'Towards an integrated approach to cultural heritage for Europe', COM (2014) 477 final, https://ec.europa.eu/assets/eac/culture/library/ publications/2014-heritage-communication_en.pdf (accessed 13 July 2019).

Guzmán, P.C., A.R.P. Roders and B.J.F. Colenbrander (2017), 'Measuring links between cultural heritage management and sustainable urban development: An overview of global monitoring tools', Cities, 60 (Part A), 192-201.

Hall, S. (1999), 'Whose heritage? Un-settling "the heritage", re-imagining the Postnation', Third Text, 13 (49), 3-13, doi: 10.1080/09528829908576818. 
Labadi, S. and W. Logan (2015), Urban Heritage, Development and Sustainability: International Frameworks, National and Local Governance, London and New York: Routledge.

Pendlebury, J. and H. Porfyriou (2017), 'Heritage, urban regeneration and place-making', Journal of Urban Design, 22 (4), 429-32, doi: 10.1080/13574809.20 17.1326712.

Pereira Roders, A. and F. Bandarin (eds) (2019), Reshaping Urban Conservation: The Historic Urban Landscape Approach in Action, Springer Singapore.

Shore, C., S. Wright and D. Però (eds) (2011), Policy Worlds: Anthropology and Analysis of Contemporary Power, New York and Oxford: Berghahn.

Sinclair-Chapman, V. (2018), '(De)Constructing symbols: Charlottesville, the confederate flag, and a case for disrupting symbolic meaning', Politics, Groups, and Identities, 6 (2), 316-23.

Sjölander-Lindqvist, A., M. Johansson and C. Sandström (2015), 'Individual and collective responses to large carnivore management: The roles of trust, representation, knowledge spheres, communication and leadership', Wildlife Biology, 21 (3), 175-85.

Sjölander-Lindqvist, A., A. Bendz, S. Cinque and C. Sandström (2018) 'Research amidst the contentious issue of wolf presence: Exploration of reference frames and social, cultural, and political dimensions', in T. Hovardas (ed.), Large Carnivore Conservation and Management: Human Dimensions, London and New York: Routledge, 19-36.

Strang, V. (2009), Gardening the World: Agency, Identity, and the Ownership of Water, New York and Oxford: Berghahn.

Toda, M. (1976), 'The decision process: A perspective', International Journal of General Systems, 3 (2), 79-88.

UN (2016), Goal 11, Sustainable Development Knowledge Platform, https://sustainabled evelopment.un.org/sdg11 (accessed 7 August 2017).

UNESCO (2016), Culture: Urban Future: Global Report on Culture for Sustainable Urban Development.

Veldpaus, L. and J. Pendlebury (2019), 'Heritage as a vehicle for development: The case of Bigg Market, Newcastle upon Tyne', Planning Practice and Research, doi: 10.1080/02697459.2019.1637168. 